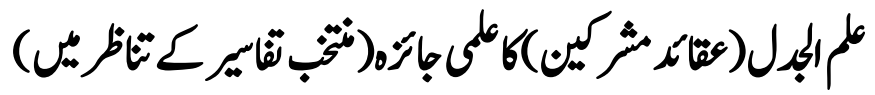

\section{An Analysis of Ayat-e-Mukhasama Related to the Beliefs of Mushrikeen in the Light of Some Selected Quranic Commentaries}

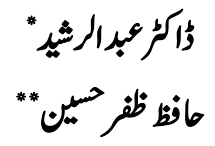

\begin{abstract}
The purpose of this article is to identify those verses of the Holy Quran wherein Allah Almighty has argued at great length with the non believers(Mushrikeen) regarding their false beliefs towards, Tauheed (Oneness of Allah Almighty), Resalate (Prophet hood),Holy Books, Angels and Akherat etc. To form a holistic approach towards the understanding of the related verses, Which is called Ayate-Mukhasama (Dialogue).
\end{abstract}

Some authentic and famous Quranic commentaries (Tafaseer) of the early three centuries of the Islamic Era (Quroon-E-Salasa) have been selected.

They include Tafseer-ul-Quran Al-karim ( Tafseer-e-Mujahid), Kitab-u-Tafseer (Tafseer-e-Suri), Tafseer Al-Kabir (Tafseer-e-Muqatil bin Sulaiman), Tafseerul-Quran Al-Azeem (Tafseer-e-Tastari), Tafseer-ul-Quran Al-Aziz (Tafseer-eAbdur Razaq)and Tafseer-e-Shafei by Imam Shafi etc.

In the light of the Holy verses, well explained by the Quranic commentaries concerned, the false beliefs of the non-believers have been discussed, assessed and then dismissed.

Keywords: Ayat-e-Mukhasama,Mushrikeen, Belifes, Holy Quran, Quranic Commentaries.

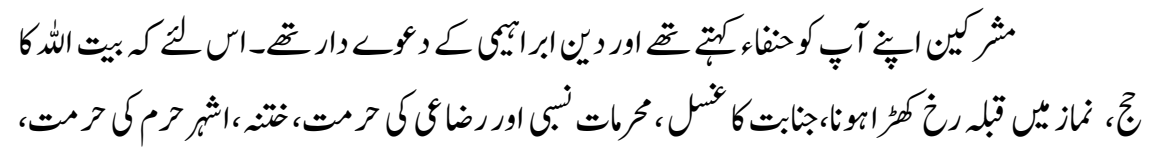

\footnotetext{
* Dr.Abdur Rashid : Subject Specialist E\&S Education Department KP.

** Dr. Hafiz Zafar Hussain :Asistant Professor Department of Islamic Theology Islamia College University Peshawar
} 


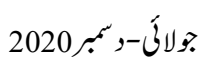

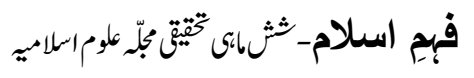

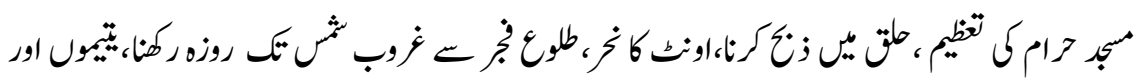

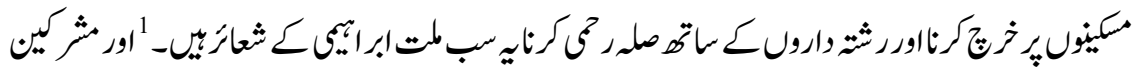

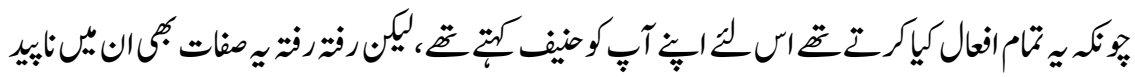

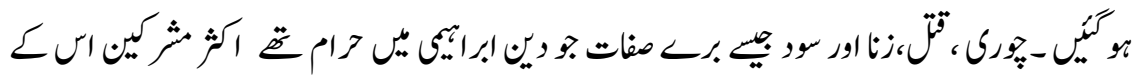

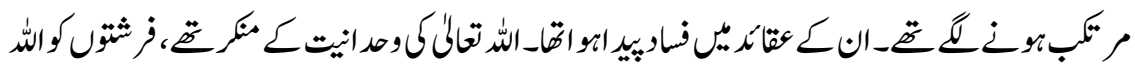

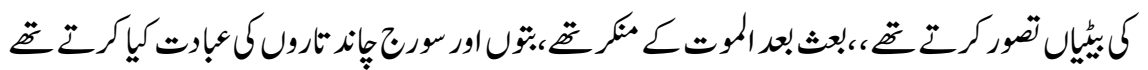

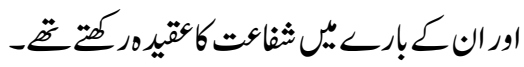

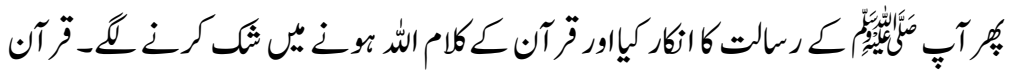

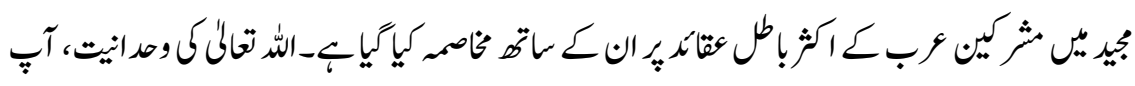

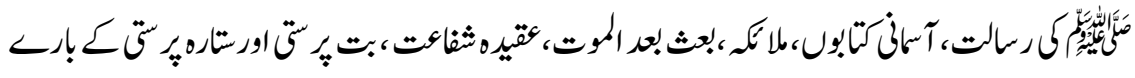

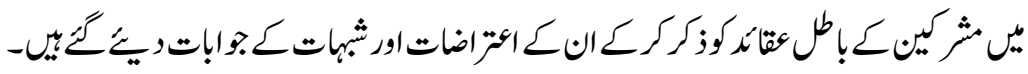

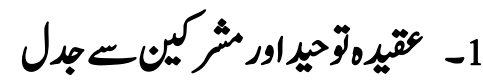

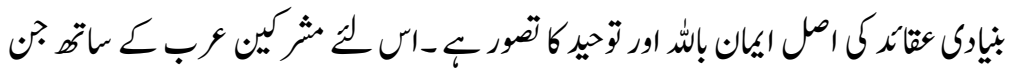

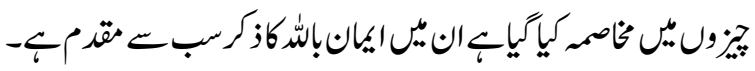

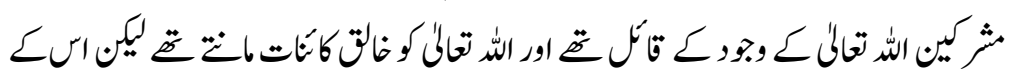

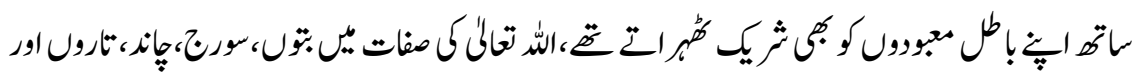

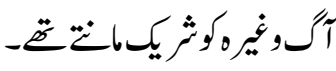

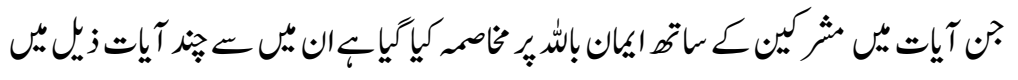

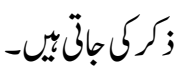

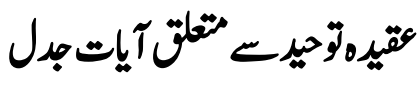

1.

2.

78 
4 4...................

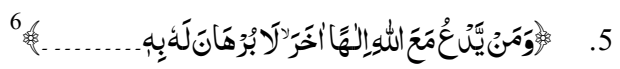

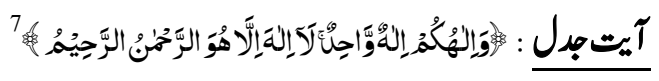
آيت جبلاور ثنمير آراء

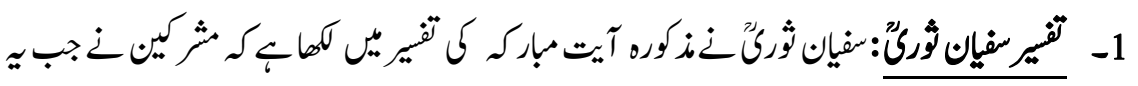

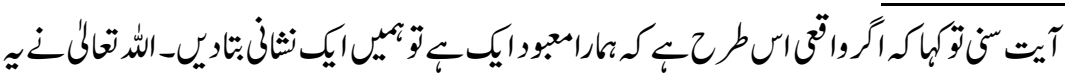

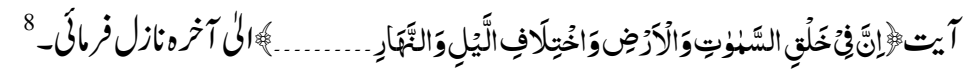

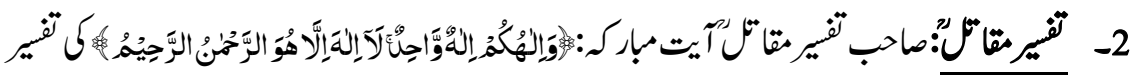

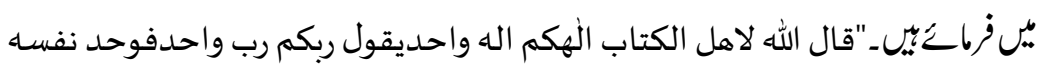
تبارك اسمه لا اله الاهوالرحمن الرحيم"-.

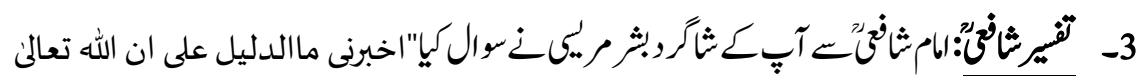

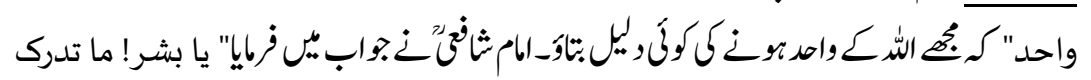

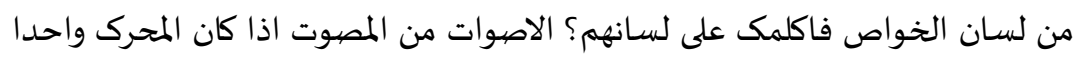

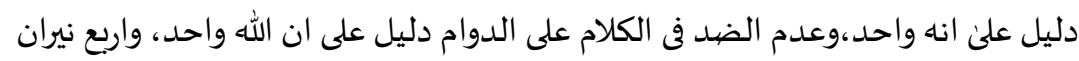

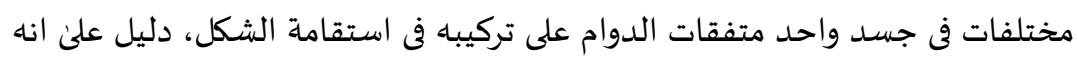

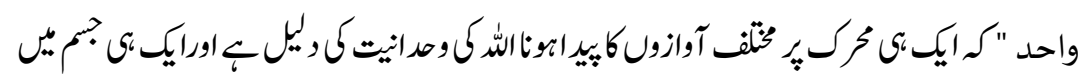

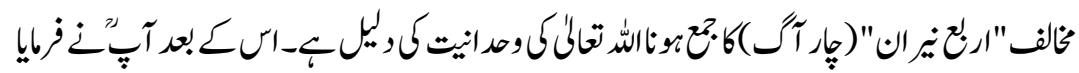

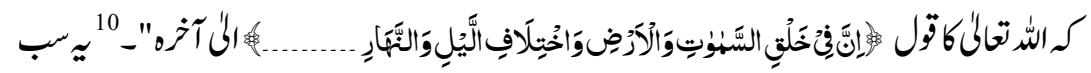

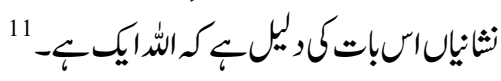

\section{2- عقيرهرمالتاورمخ كئنس جبل}

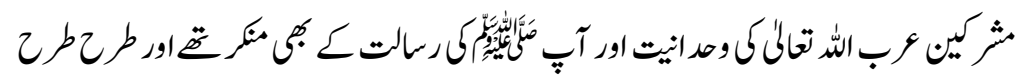

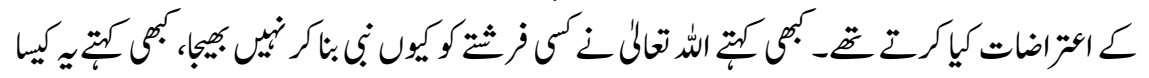




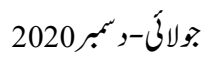

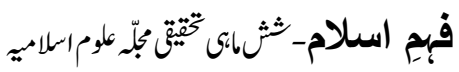

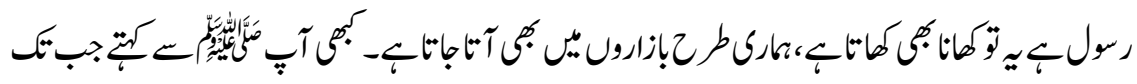

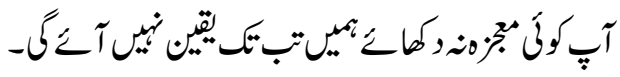

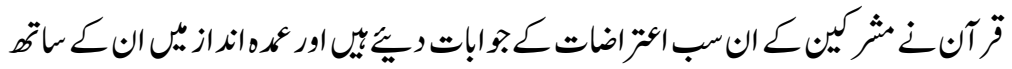

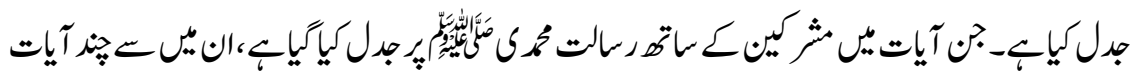

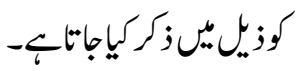

آيات جدلاورعقيرهرمالت

12 留.

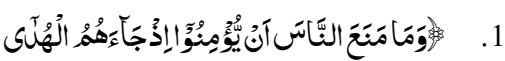

13 留 2.

14

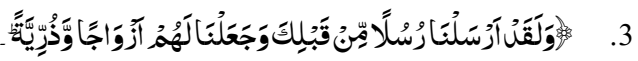
15

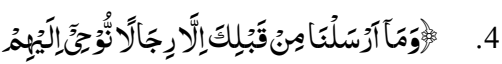

آيتِ بدل: 16

آيت جدل اور ثضمى آراء

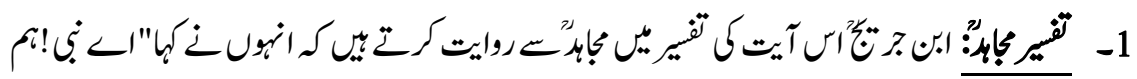

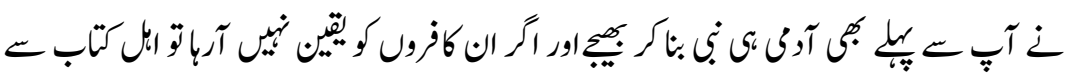

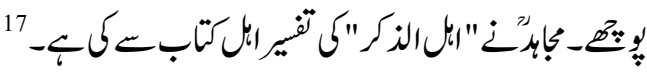

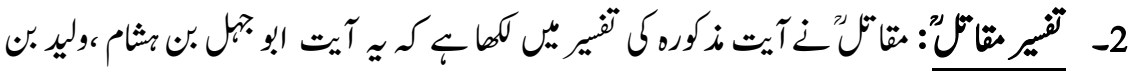

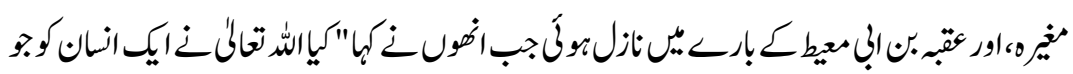

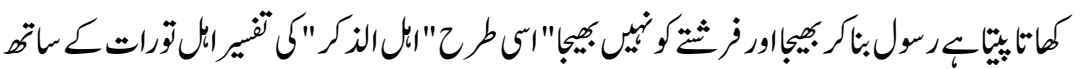

$18-45$

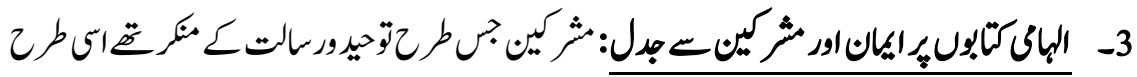

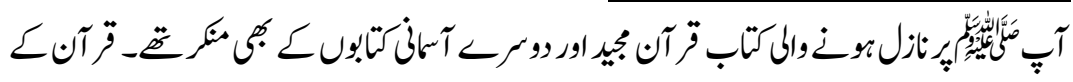

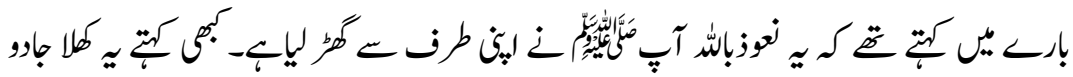

80 


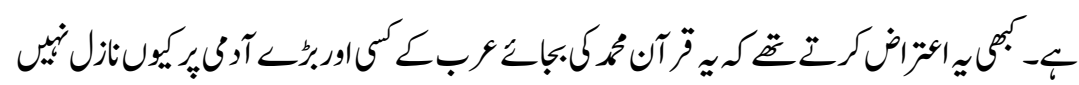

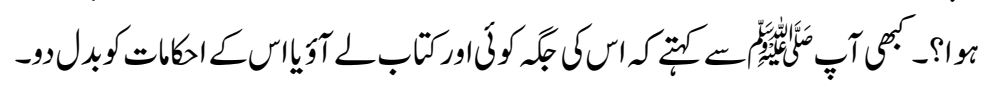

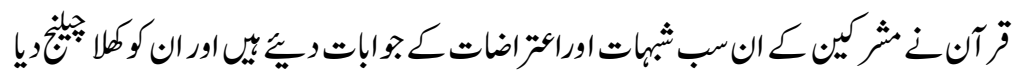

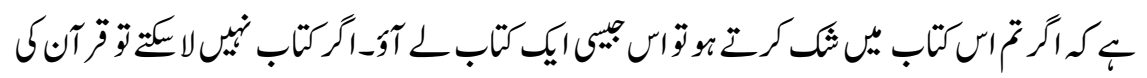

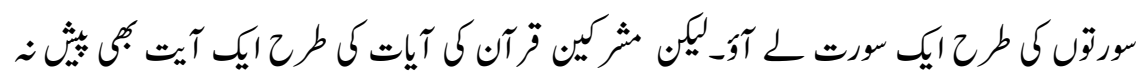

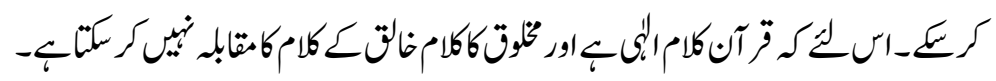

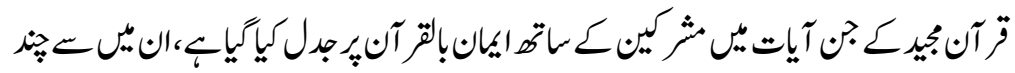

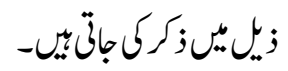

\section{زَ آنيءايكان اور آيات جبل}

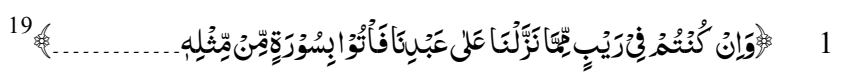
20 20....................

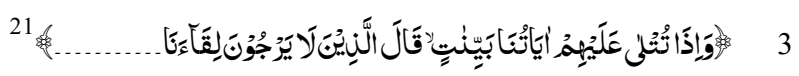

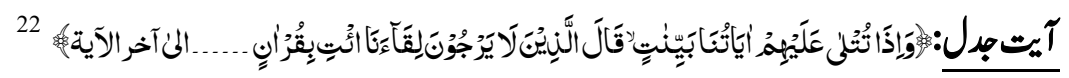

\section{آيت جبلاورثيرى آراء}

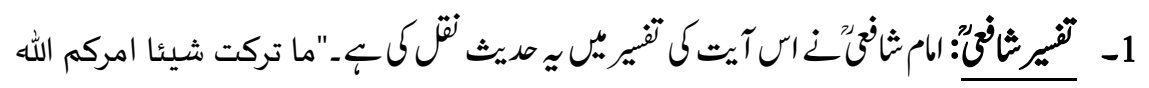

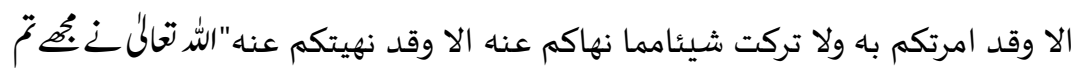

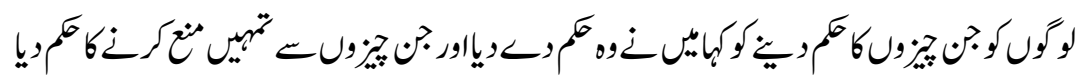

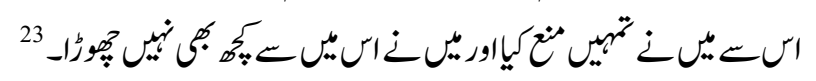

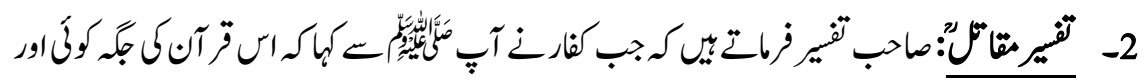

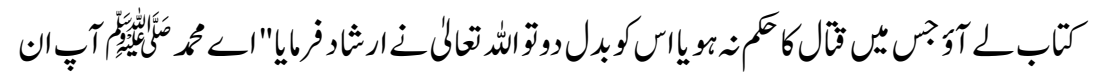

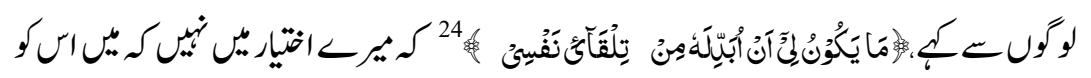

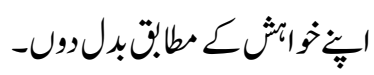




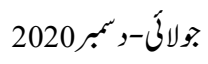

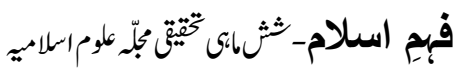

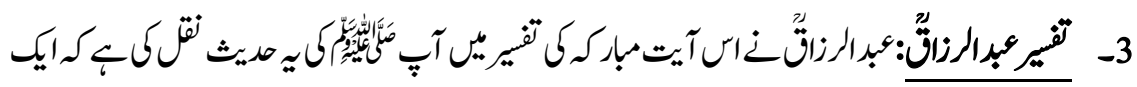

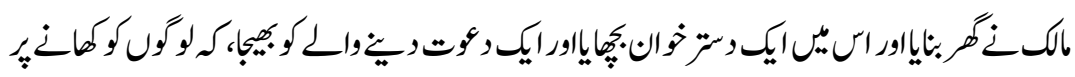

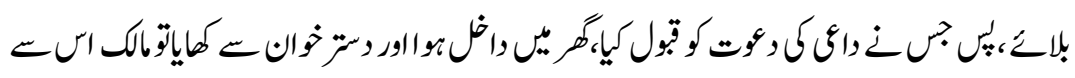

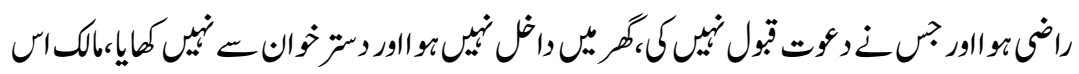

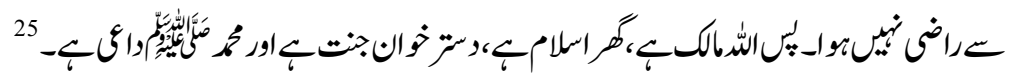

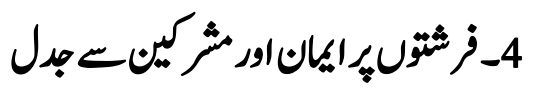

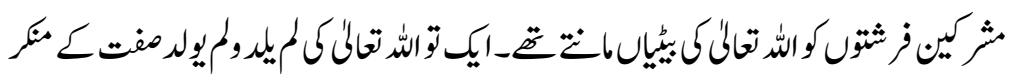

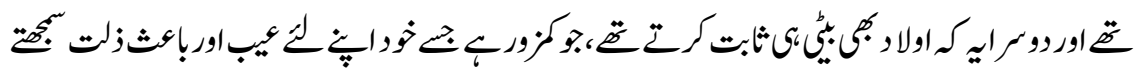

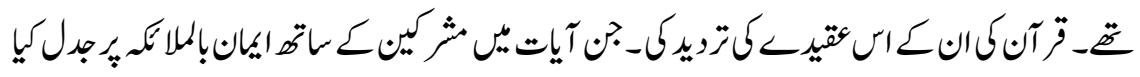

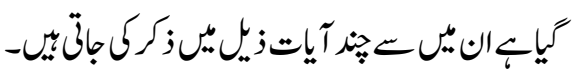

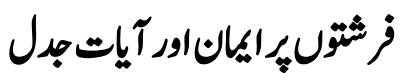

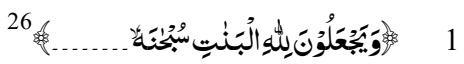

27 留 2

28 㔉

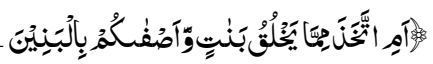

3

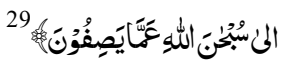

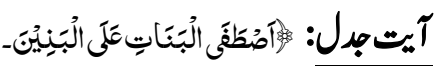

آيت جدل اور ثضمرك آراء

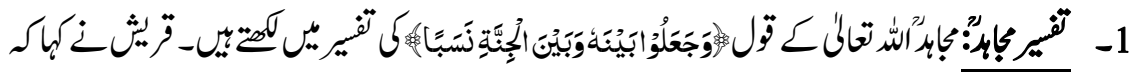

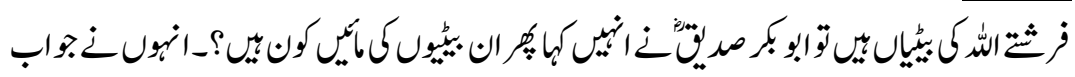

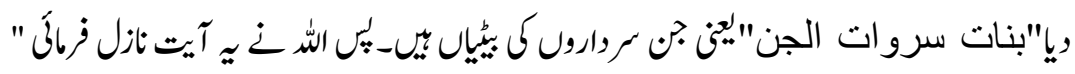

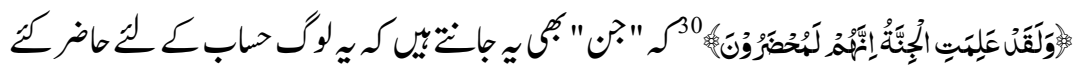

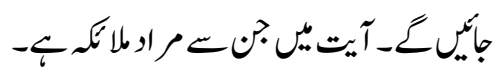

82 


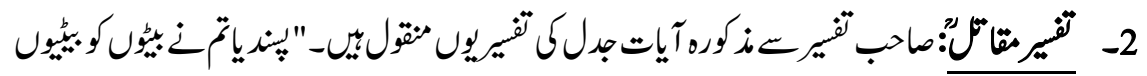

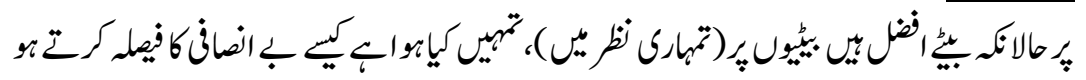

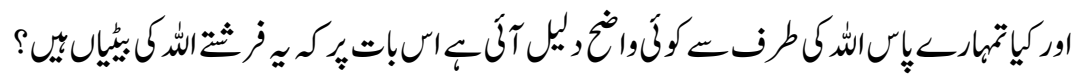

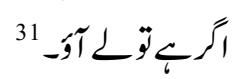

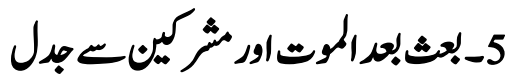

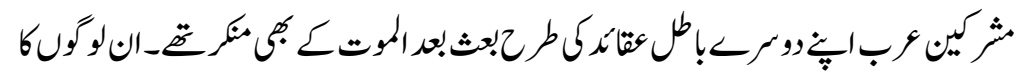

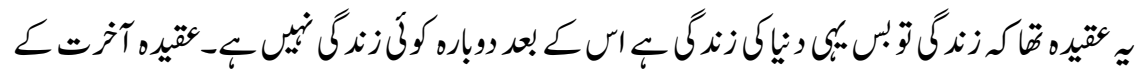

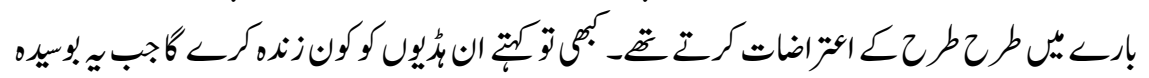

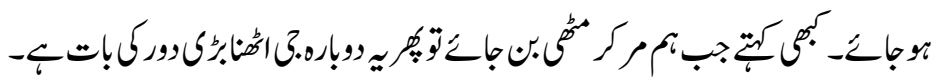

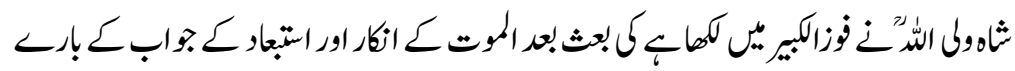

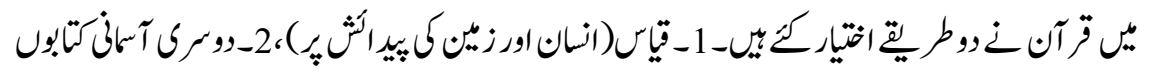

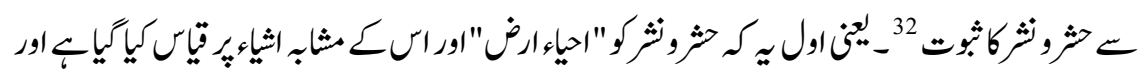

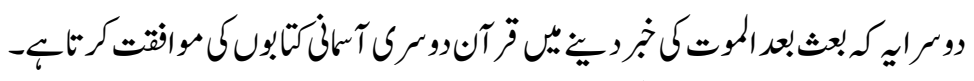

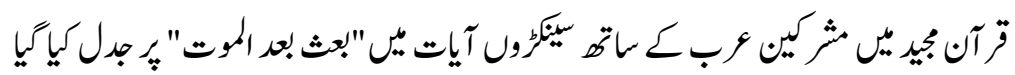

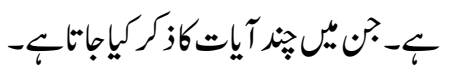

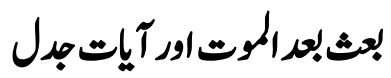

${ }^{33} 3$

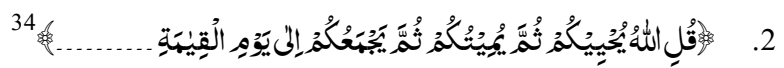
${ }^{35} \operatorname{sen}_{1}$ 3.

\section{آيات جدلاورثيرى آراء}

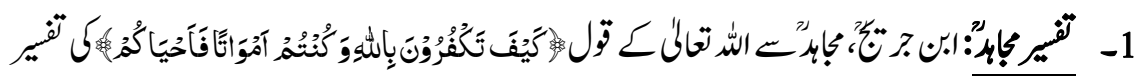

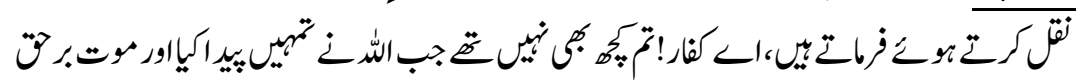




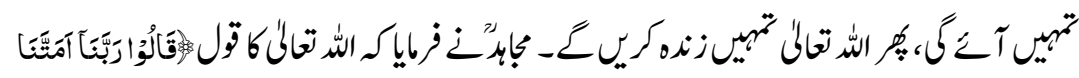

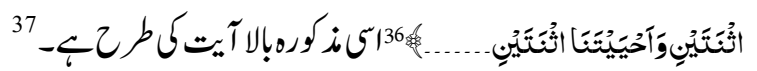

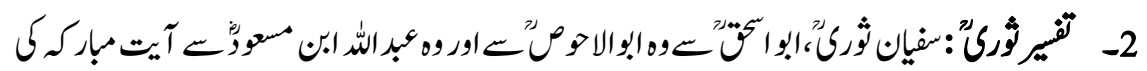

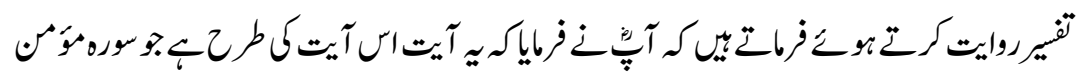

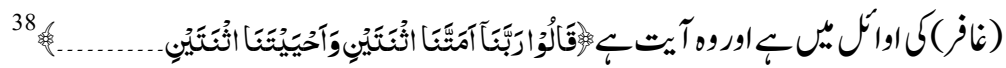

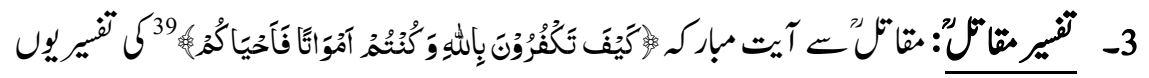
مثقول بيل." كيف تكفرون بالله (بانه واحدلاشريك له) وكنتم امواتا يعنى نطفافاحياكم يعنى فخلقكم ثم يميتكم عنداحيائكم ثم يحييكم من بعدالموت يوم القيامةثم اليه

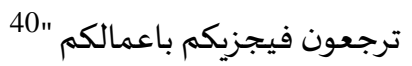

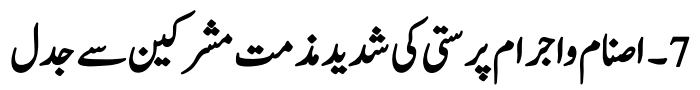

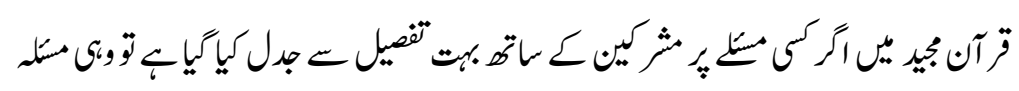

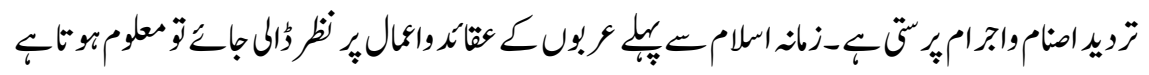

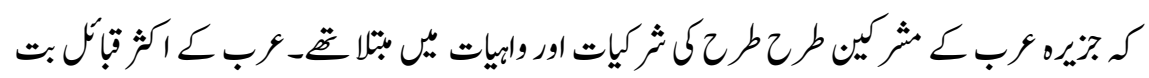

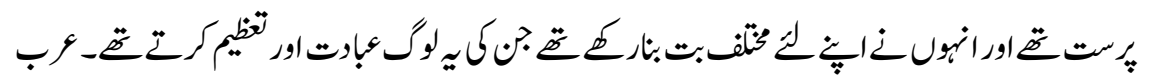

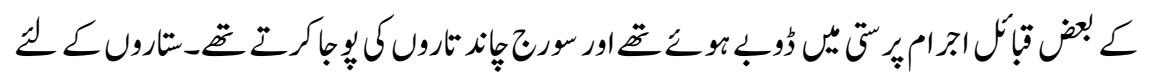

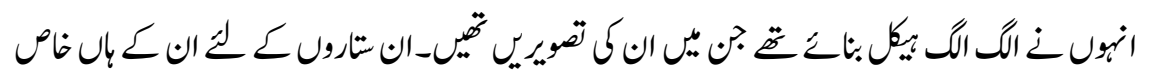

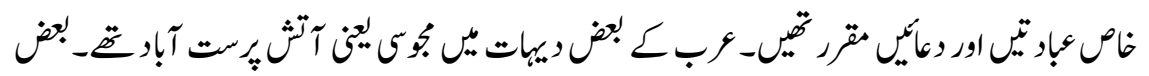

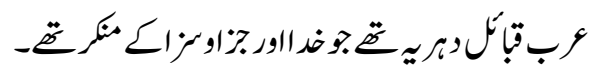

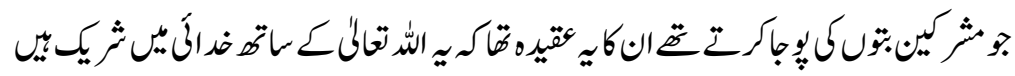

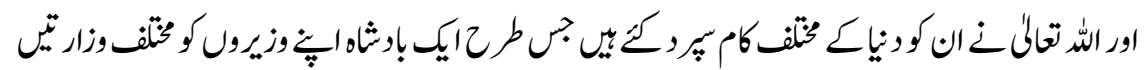

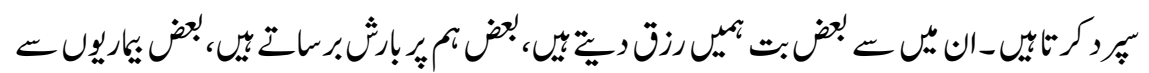

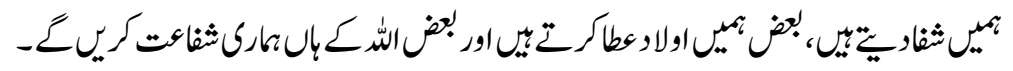




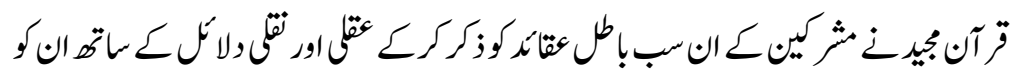

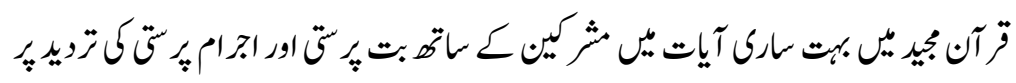

روكياب

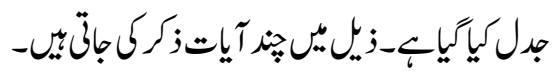

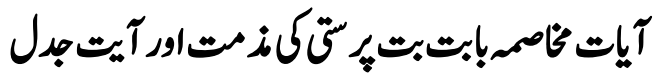

${ }^{41}{ }^{\prime}$

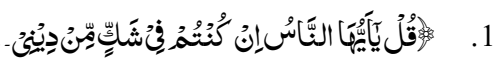
42 2. ${ }^{43}$ 3.

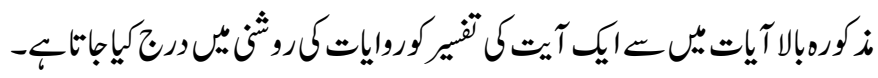

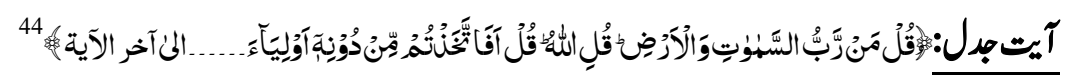

\section{آيت جبلاورتيزرى آراء}

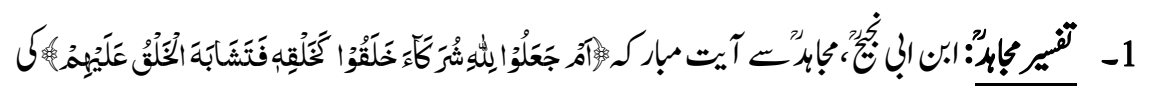

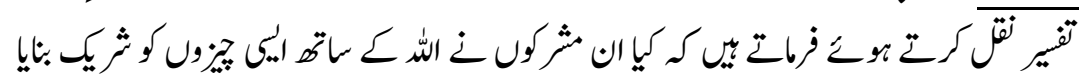

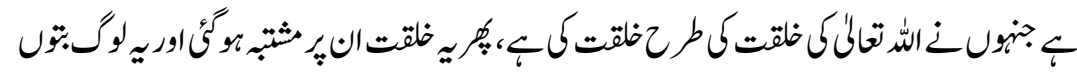

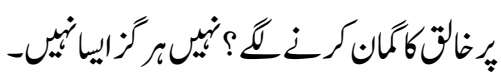

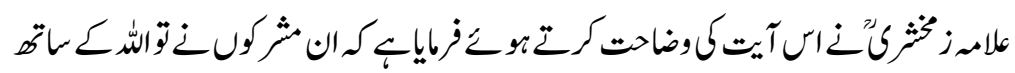

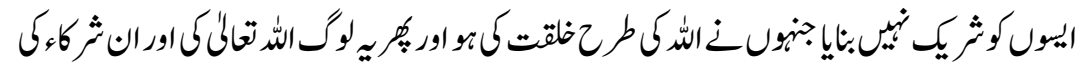

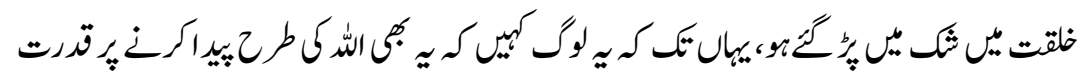

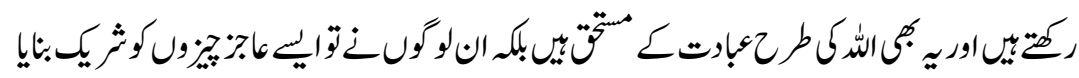

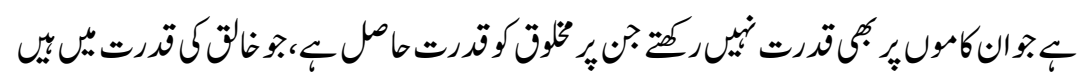

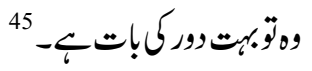

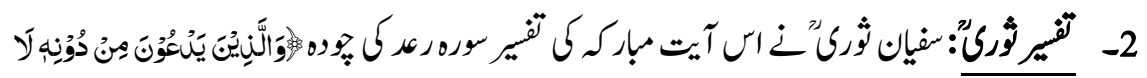

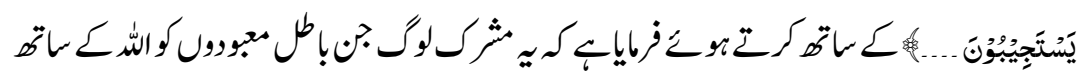




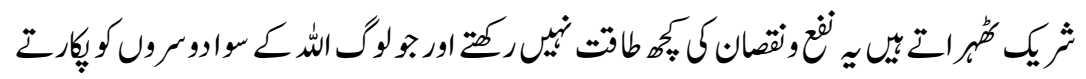

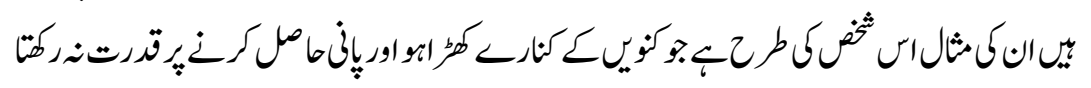

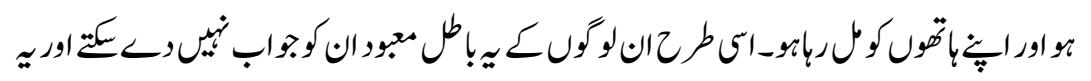

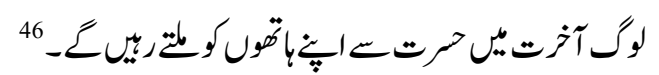

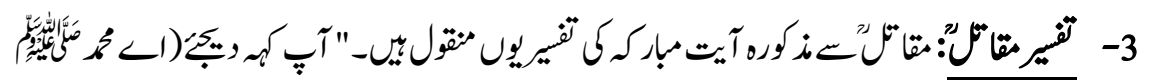

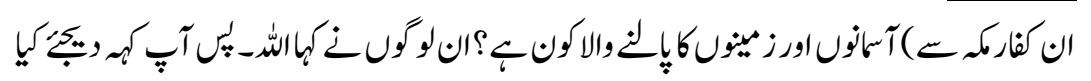

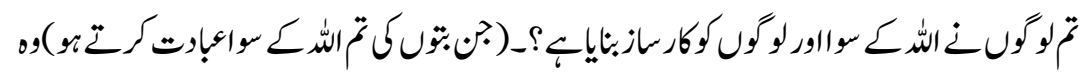

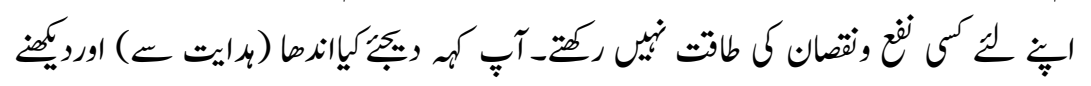

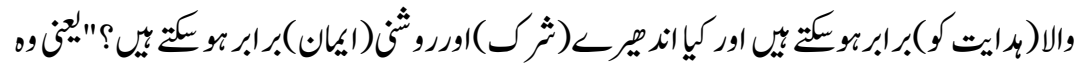

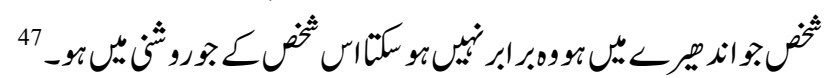

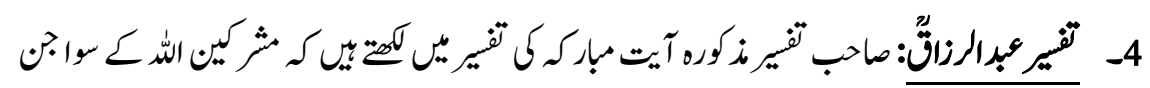

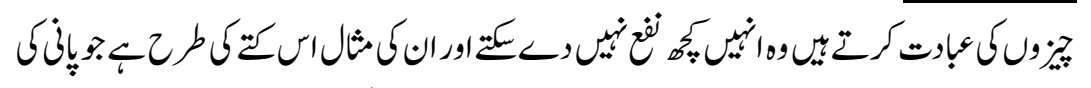

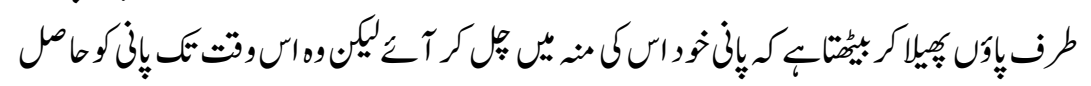

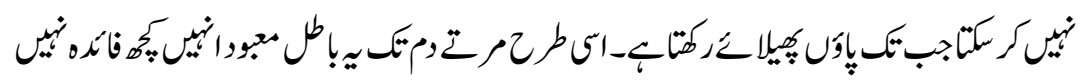

48 بن

$$
\text { 1- } 1
$$

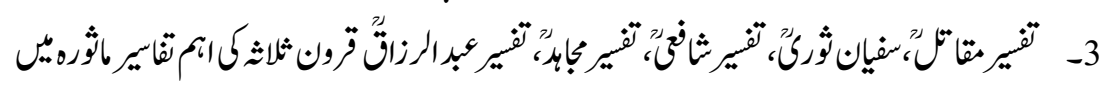

-

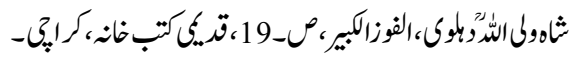
مورهبتر-163 


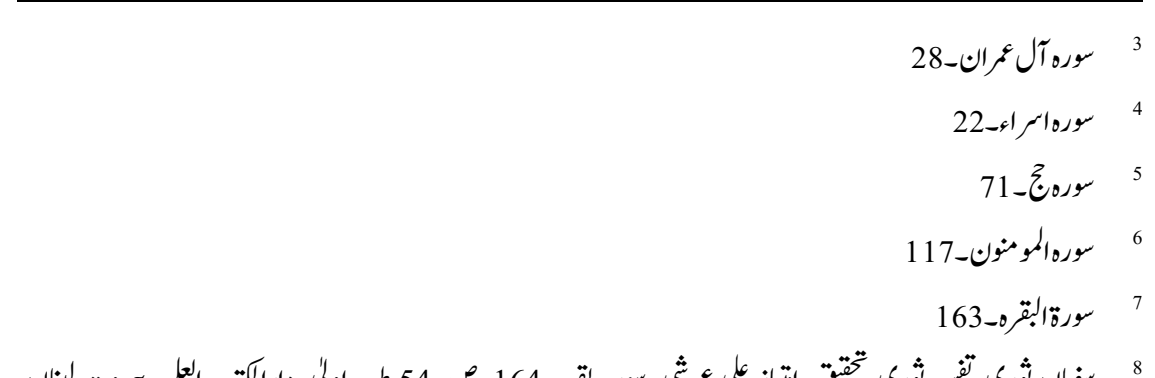

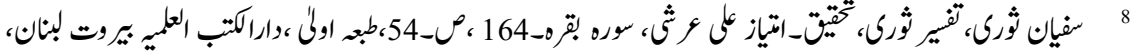
- 1403

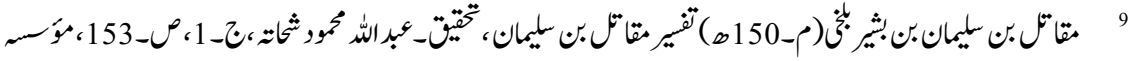

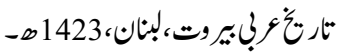

$$
10
$$

11

$$
13 \text { } 13 \text { } 13
$$

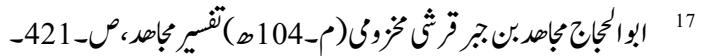

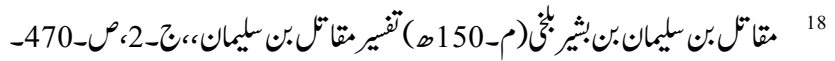

$$
22 \text { } 219
$$

24

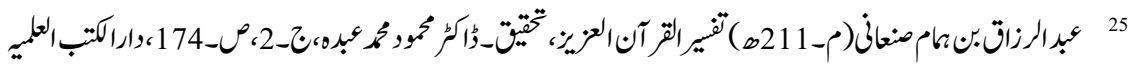
بيروت، لبنان،1419هـ

$$
\text { 59-57، } 26
$$




$$
2829
$$

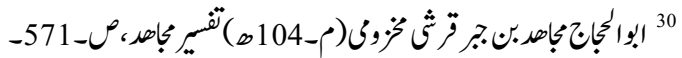

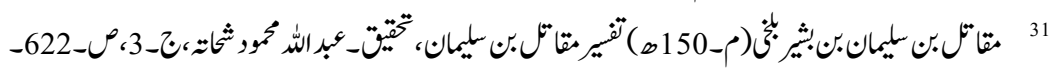
32

$$
33 \text { 36 } 35
$$

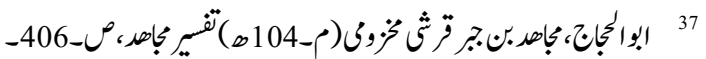

$$
38
$$

$$
\text { rN_0 } 39
$$

40

$$
412
$$

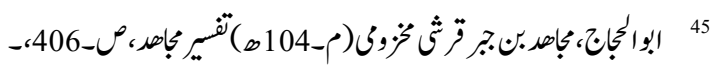

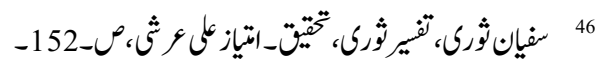

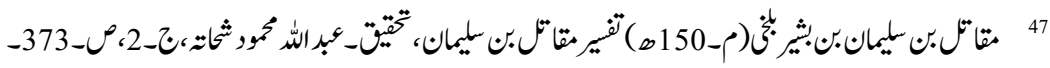

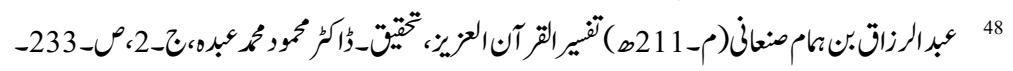

